\title{
Platelet Derived Growth Factor And The Extent Of Skin Thickening As Potential Indicators Of Pulmonary Affection In Systemic Sclerosis
}

\author{
Manal Mahmoud, Mona El Fangary*, Aya M Abdel Dayem**, \\ Nesriene EI Margoushy***, Mohamed Said***** \\ Internal Medicine Ain Shams University, *Dermatology Department Misr University for \\ Science and Technology, ${ }^{* *}$ Chest Department Ain Shams University, ${ }^{* * *}$ Medical and \\ Radiation Research Department, Nuclear Material Authority, ****Biochemistry \\ Respiratory Intensive Care Unit Ain Shams University.
}

\section{Abstract}

Background and objective: Systemic sclerosis is a multisystem disease that has considerable variability in its presentation, course, and prognosis. The aim of this study was to determine serum levels of platelet-derived growth factor (PDGF A/B) in patients with systemic sclerosis (SSc) and to correlate these levels with the extent of skin sclerosis and presence of pulmonary affection. Moreover, the efficiency of PDGF and skin score in early detection of pulmonary affection were assessed.

Patients and methods:The study included 22 female patients with SSc (according to the American College of Rheumatology) (Masi et al., 1980) and 15 age-matched healthy control females. According to the classification by LeRoy et al. (1988), we divided our patients into limited SSc (10 patients-45.5\%) and diffuse SSc (12 patients$54.5 \%$ ). The extent of skin sclerosis was assessed by the modified Rodnan total skin thickness scoring (TSS) system (Clements et al.,1995). In our study, patients with limited SSc had a skin score $<25$, while those with diffuse SSc had skin score $>25$. Five diffuse SSc patients had associated pulmonary affection, diagnosed by history taking, clinical examination, chest x-ray, arterial blood gases, spirometry and diffusing capacity of the lung for carbon monoxide (DLCO). Serum levels of PDGF were determined in SSc patients and healthy controls using quantitative sandwich ELISA technique.

Results: Serum PDGF mean and standard deviation in healthy subjects was $5.2 \pm 2.466 \mathrm{ug} / \mathrm{l}$. PDGF values showed continuous significant increment with progression of the disease. Mean PDGF serum levels in limited SSc, diffuse SSc without pulmonary affection and with pulmonary affection were $15.8 \pm 2.3,20.86 \pm 2.41$ and $32 \pm 3.08 \mathrm{ug} / \mathrm{l}$, respectively. Furthermore, the results revealed that PDGF value $<10 \mathrm{ug} / \mathrm{l}$, tend to exclude the diagnosis of SSc with $100 \%$ sensitivity and specificity, respectively. Moreover, all patients with diffuse SSc and having pulmonary affection had PDGF values $>25 \mathrm{ug} / \mathrm{l}$. This value provided a diagnostic sensitivity and specificity of $100 \%$.

As regards the total skin score, a statistical significance was found between limited and diffuse SSc but did not show a statistically significant difference between SSc patients with $(32.2 \pm 4.49)$ and without $(29.71 \pm 3.25)$ pulmonary affection (p>0.05). However, in patients with diffuse SSc, PDGF levels tended to correlate positively with the skin score $(\mathrm{p}=0.05)$. ROC plot showed that skin score at a value of 29 was the best cut-off level to diagnose pulmonary affection in patients with diffuse SSc with a diagnostic sensitivity of $80 \%$ and specificity of $71.4 \%$.

Conclusion: PDGF is a simple and easy laboratory test that tends to exclude the presence of SSc at a cut-off value of $10 \mathrm{ng} / \mathrm{ml}$ with $100 \%$ sensitivity and specificity, respectively. PDGF correlates positively with extent of skin involvement and significantly with pulmonary affection. PDGF and skin scoring system are simple laboratory and physical measures for evaluating patients with systemic sclerosis with cutoff levels of $25 \mathrm{ug} / \mathrm{l}$, and 29 respectively in detecting pulmonary affection. However, 


\section{Manal Mahmoud et al}

further studies are recommended on larger population to ensure the diagnostic efficiency of PDGF and to test the applicability of our obtained cut-off values.

\section{Introduction}

Systemic sclerosis is a multisystem disorder characterized by fibrotic and degenerative changes in the skin, blood vessels and various internal organs (Allanore and Kahan, 2006). It frequently affects the lung and interstitial pulmonary fibrosis is one of its major complications (Highland and Silver, 2005). The disease is highly variable in its presentation. At one end of the spectrum are patients with limited scleroderma in whom skin thickening is relatively restricted to the fingers, hands and face, and internal organ compromise is delayed for several years (Rodnan et al., 1979). At the other end of the spectrum are patients with diffuse scleroderma in whom skin changes are widely spread and progresses rapidly to involve distal and proximal extremities and the trunk. Visceral complications occur relatively early and tend to be serious (Steen et al., 1980).

Although the pathogenesis of this disease remains unknown, there are three major processes that contribute to the clinical manifestations of SSc: first, severe tissue fibrosis with excessive deposition of collagen and connective tissue components in the extra-cellular matrix; second, chronic inflammation characterized by infiltration of $\mathrm{T}$ cells and macrophages in affected tissues; and third, micro-vascular disease, characterized by intimal proliferation of blood vessels (Jiminez and Derk, 2004). Fibrosis can be caused by profibrotic cytokines that are released from inflammatory cells infiltrating the affected tissues, including transforming growth factor- $\beta$ (TGF- $\beta$ ), interleukin-4 (IL-4), platelet derived growth factor (PDGF), and connective tissue growth factor (CTGF) (Sakkas, 2005).

Transforming growth factor- $\beta$ (TGF- $\beta$ ) is likely to be one of the most significant candidates responsible for fibrosis in systemic sclerosis (Krein and Winston, 2002). This cytokine is produced by many neoplastic cells and by most normal cells, including endothelial cells, macrophages and lymphocytes (Sapadin et al., 2001). It is a potent chemotactic agent for monocytes and fibroblasts (Alaibac et al., 2006).

Interestingly, TGF- $\beta$ was found to have an indirect mitogenic activity on fibroblasts. It was found that this mitogenic activity appears to be dependent on the autocrine production of platelet-derived growth factor (PDGF) related peptides (Paulsson et al., 2004).

PDGF is selectively induced in fibroblasts after activation with TGF- $\beta$. Thus, PDGF may act as a mediator of TGF$\beta$ action on connective tissue cells, where it stimulates cell proliferation and extracellular matrix (ECM) synthesis (Sapadin et al., 2001).

Many respiratory manifestations have been described in association with collagenosis. The resulting abnormalities of pulmonary function in affected patients include restrictive ventilatory defect, airflow obstruction, and a depressed diffusing capacity for carbon monoxide, which may be an isolated early finding often before chest radiograph (Chiappini et al., 2005).

\section{The aim of the work}

The aim of this study was to determine serum levels of platelet-derived growth factor (PDGF) in patients with systemic sclerosis (SSc) and to correlate these levels with the extent of skin sclerosis and presence of pulmonary affection. Moreover, the efficiency of PDGF and skin score in early detection of pulmonary affection were assessed.

\section{Patients and methods}

This study included 22 female patients with definite systemic sclerosis classified according to the preliminary criteria of the American College of Rheumatology (ACR) (Masi et al., 1980). Fifteen age-matched female subjects were also included in the 
study and served as a control group (Group I).

As regards the SSc patients, they were selected from those attending the Rheumatology and Rehabilitation as well as Dermatology outpatient clinics, Ain Shams University and Misr University for Science and Technology (MUST) hospitals. Ten of these patients $(45.5 \%)$ had limited SSc (Group II) while the remaining twelve patients $(54.5 \%)$ had diffuse SSc (Group III) according to the classification proposed by Le Roy et al. (1988). Among the diffuse SSc patients, five subjects had evidence of pulmonary fibrosis (group IIIA) while the remaining seven subjects (group IIIB) did not have any pulmonary manifestations.

\section{All the patients were subjected to the following:}

A - History taking including onset, course and duration of the disease.

B- Assessment of skin involvement and its extent depending on the modified Rodnan total skin thickness scoring (TSS) system (Clements et al.,1995). It employs a quantitative rating scale $(0$, normal skin; 1 , mild skin thickening; 2 , moderate skin thickening unable to pinch; 3, severe skin thickening unable to move) of the findings on clinical palpation of 17 body areas (face, anterior chest, abdomen, left and right fingers, dorsum of left and right hand, left and right forearm, left and right upper arm, left and right thigh, left and right leg, dorsum of left and right foot). The skin score for each patient was derived by the summation of the scores from all 17-body areas, with a maximum score of 51.

C- Assessment of systemic affection including:

1. Joint affection, which may be in the form of inflammatory polyarthralgia or arthritis.

2. Proximal muscle weakness.

3. Clinical examination of the heart to detect pericarditis, congestive heart failure or arrhythmias.

4. Clinical assessment of the kidney.

5. Manometry to detect oesophageal dysmotility
6. Pulmonary involvement judged by:

-Chest symptoms mainly dyspnea and cough.

-Chest signs including bilateral leathery crepitation.

-Chest x-ray showing reticular, nodular and reticulonodular patterns (P.A. view). -Arterial blood gas (ABG) analysis.

-Pulmonary function tests done using flow mate model 2500 spirometer to calculate the following indices:

- Forced vital capacity (FVC).

- Forced expiratory volume at one second (FEV1).

- Ratio of FEV1 to FVC expressed as a percentage (FEV1 / FVC \%).

- Maximal mid-expiratory flow rate (MMEF).

-Diffusing capacity of the lung for carbon monoxide (DLCO) was measured using "Morgan Transfer Test model C" using single breath method.

They were considered to be abnormal if FVC, FEV1, FEV1 / FVC, MMEF and DLCO $<75 \%$ of the normal values of the control group (Cotes, 1975) and (Sato et al., 2000).

D- Laboratory assessment:

Sampling: A venous blood sample $(6 \mathrm{ml})$ was withdrawn from all participants. Three millilitres were collected in EDTAcontaining vaccutainers and were subjected for the determination of blood counts and ESR. The other $3 \mathrm{ml}$ was collected in plain vaccutainers and the separated sera were divided into two aliquots. The first aliquot was used for the assay of serum creatinine while the other aliquot was rapidly frozen at $-70^{\circ} \mathrm{C}$ for future assay of PDGF as it has been reported that EDTA and citrate interfere with its assay.

Timed urine samples were collected for the assay of urinary creatinine for further calculation of creatinine clearance and for routine urine examination.

\section{Analytical Procedure:}

-Complete blood counts were done using Coulter Counter micro-diff. 18 (Coulter Corporation, Miami, Florida, USA). -ESR (using Westergren method). 


\section{Manal Mahmoud et al}

-Serum and urinary creatinine were assayed using Synchron $\mathrm{Cx}-5$ Delta auto analyzer of Beckman (Beckman instruments Inc. Fullerton, USA). Creatinine clearance rate was calculated.

-Detection of serum levels of PDGF A/B

Recombinant human PDGF A/B was purchased from Roche Diagnostics (Roche Diagnostics $\mathrm{GmbH}$, Molecular Biochemical, Mannheim, Germany). Other reagents were purchased from Gibco (Gibco BRL, Gaithersburg, MD, USA).

In this assay procedure, ninety-six well plates were coated with antihuman PDGF $\mathrm{MoAb}$ for $1 \mathrm{hr}$ at room temperature and were blocked with blocking reagent for 2 hours at room temperature. Serum samples $(50 \mu \mathrm{l})$ were added to the wells for $1 \mathrm{hr}$, followed by incubation with biotinylated antihuman PDGF MoAb for $1 \mathrm{hr}$ at room temperature. The plates were incubated with a 1:1000 dilution of streptavidin- $\beta$ - $D$ galactosidase for 1 hour subsequently. One percent of 4-Methyl-umbellifery-b-D galactoside was added to the wells (Sigma Chemicals Co. St. Louis, USA). The fluorescence intensity of the wells was determined at $460 \mathrm{~nm}$ using the Organon reader 530 (Organon, Germany).

Statistical analysis This was done using a PC with Microstat ${ }^{\mathrm{TM}}$ software. Parametric tests were used as the obtained data proved to be normally distributed by the goodness of fit test. Descriptive statistics of the obtained data was presented as mean and standard deviation. Difference between the means of each two groups was tested using Student's $t$-test. Correlation study was done by calculating the correlation coefficient ${ }^{\circledR}$. $P$ values $<0.05$ were considered significant.

Receiver characteristic curve (ROC) plots were constructed after calculating the diagnostic sensitivities and specificities at different values. Cut-off values were chosen according to the ROC plots that determine the point having the greatest sum of sensitivity and specificity.

\section{Results}

Clinical and radiological findings in patients with diffuse SSc are shown in table
1. Pulmonary function tests of the different groups of patients, namely those with limited SSc, diffuse SSc with and without pulmonary affection are shown in table 2 and 3. Our results showed that DLCO and FVC are better reflectants to the pulmonary function status of the patients than $\mathrm{FEV}_{1} / \mathrm{FVC}$ ratio, MMEF, $\mathrm{pH}, \mathrm{PaCO}_{2}$ and $\mathrm{PaO}_{2}$.

As regards PDGF (table 4), our results showed that SSc patients had significantly higher levels of PDGF than healthy subjects ( $p<0.001$ ). Moreover, PDGF values showed continuous significant increment with the progression of the disease. However, none of the SSc patients in this study had PDGF value $<10 \mathrm{ug} / \mathrm{l}$. So values $\leq 10 \mathrm{ug} / \mathrm{l}$. tend to exclude the diagnosis of SSc with $100 \%$ sensitivity and specificity. Similarly, none of the patients with diffuse SSc and presenting with pulmonary function affection had PDGF < $25 \mathrm{ug} / \mathrm{l}$; ; so values $>25 \mathrm{ug} / \mathrm{l}$., can predict the occurrence of pulmonary affection with $100 \%$ sensitivity and specificity.

A significant positive correlation existed between PDGF values and duration of the disease in patients with diffuse SSc ( $p$ <0.05). PDGF correlated negatively with DLCO in groups II and III $(\mathrm{p}<0.05)$. As regards the FVC, PDGF was negatively correlated to FVC in patients with diffuse $\mathrm{SSc}$ (group III) where $\mathrm{p}<0.05$.

As regards the total skin score (table 5), it did not show any statistical significant difference between SSc patients with and without pulmonary affection ( $>>0.05)$. However, there was a tendency of a positive correlation between the skin score and PDGF levels in patients with diffuse SSc $(p=0.05)$. There was an inverse correlation between DLCO and skin score in diffuse SSc patients $(\mathrm{p}<0.05)$.

Receiver characteristic curve (ROC) plots revealed that a skin score of 29 was the best cut-off to predict the occurrence of pulmonary affection in patients with diffuse SSc and had a diagnostic sensitivity of $80 \%$ and specificity of $71.4 \%$ (Fig 1). On the other hand, PDGF at a cut-off value of $25 \mathrm{ug} / \mathrm{l}$., had a diagnostic sensitivity and specificity of $100 \%$, in detecting the presence of pulmonary affection in patients with diffuse SSc. 
Table 1: Clinical and radiological findings in the diffuse SSc patients.

\begin{tabular}{|l|l|l|}
\cline { 2 - 3 } \multicolumn{2}{c|}{} & \multicolumn{2}{l|}{ Group III (n = 12) } \\
\hline \multirow{2}{*}{$\begin{array}{r}\text { Chest symptoms: Dyspnea } \\
\text { Cough }\end{array}$} & No. & $\%$ \\
\cline { 2 - 3 } & 8 & $66.6 \%$ \\
\hline Chest signs: (bilateral leathery crepitation) & 7 & $58.3 \%$ \\
\hline Chest radiography: (reticulonodular pattern) & 5 & $41.7 \%$ \\
\hline Arthritis or Arthralgia & 2 & $16.6 \%$ \\
\hline Heart affection & 8 & $66.6 \%$ \\
\hline Proximal muscle weakness & 1 & $8.3 \%$ \\
\hline Renal affection & 2 & $16.6 \%$ \\
\hline Esophageal dysmotility & -- & $0 \%$ \\
\hline
\end{tabular}

Table 2: Descriptive and comparative statistics of DLCO and FVC in different groups of SSc patients:

\begin{tabular}{|c|c|c|c|c|}
\hline \multirow{2}{*}{$\overline{\mathrm{DLCO}}$} & & \multirow{2}{*}{$\begin{array}{l}\text { Group II } \\
90.6\end{array}$} & \multirow{2}{*}{$\begin{array}{l}\text { Group IIIA } \\
63.6\end{array}$} & \multirow{2}{*}{$\begin{array}{l}\text { Group IIIB } \\
77.43\end{array}$} \\
\hline & Mean & & & \\
\hline & SD & 3.84 & 3.51 & 4.8 \\
\hline & Min. & 85 & 60 & 70 \\
\hline & Max. & 96 & 68 & 85 \\
\hline & & & $\mathrm{t}$ & $\mathrm{P}$ \\
\hline \multicolumn{3}{|c|}{ Group II vs. Group IIIA } & -13.189 & $<0.001$ \\
\hline \multicolumn{3}{|c|}{ Group II vs. Group IIIB } & -6.298 & $<0.001$ \\
\hline \multicolumn{3}{|c|}{ Group IIIA vs. Group IIIB } & -5.463 & $<0.001$ \\
\hline & & Group II & Group IIIA & Group IIIB \\
\hline \multirow[t]{5}{*}{ FVC } & Mean & 91.3 & 68.8 & 83.143 \\
\hline & SD & 4.692 & 2.388 & 5.429 \\
\hline & Min. & 85 & 65 & 74 \\
\hline & Max. & 98 & 71 & 90 \\
\hline & & & $\mathrm{t}$ & $\mathrm{P}$ \\
\hline \multicolumn{3}{|c|}{ Group II vs. Group IIIA } & -9.965 & $<0.001$ \\
\hline \multicolumn{3}{|c|}{ Group II vs. Group IIIB } & -3.311 & $<0.001$ \\
\hline \multicolumn{3}{|c|}{ Group IIIA vs. Group IIIB } & -5.24 & $<0.001$ \\
\hline
\end{tabular}


Table 3: Descriptive and comparative statistics of pulmonary function tests in different groups of SSc patients:

\begin{tabular}{|c|c|c|c|}
\hline & Group II & Group IIIA & Group IIIB \\
\hline $\mathrm{FEV}_{1} / \mathrm{FVC}$ & $86.5+7.7$ & $83.8+7.9$ & $85.6+7.4$ \\
\hline & & $\mathrm{t}$ & $\mathrm{P}$ \\
\hline \multicolumn{2}{|l|}{ Group II vs. Group IIIA } & 0.629 & $>0.05$ \\
\hline \multicolumn{2}{|l|}{ Group II vs. Group IIIB } & 0.243 & $>0.05$ \\
\hline \multicolumn{2}{|l|}{ Group IIIA vs. Group IIIB } & -0.399 & $>0.05$ \\
\hline \multirow[t]{2}{*}{ MMEF } & $88.2+7.4$ & $60.9 \pm 16.2$ & $70.2+36.7$ \\
\hline & & $\mathrm{t}$ & $\mathrm{P}$ \\
\hline \multicolumn{2}{|l|}{ Group II vs. Group IIIA } & 3.586 & $<0.01$ \\
\hline \multicolumn{2}{|l|}{ Group II vs. Group IIIB } & 1.28 & $>0.05$ \\
\hline \multicolumn{2}{|l|}{ Group IIIA vs. Group IIIB } & -0.594 & $>0.05$ \\
\hline \multirow[t]{2}{*}{$\mathrm{PH}$} & $7.4 \pm 0.04$ & $7.38 \pm 0.04$ & $7.43 \pm 0.05$ \\
\hline & & $\mathrm{t}$ & \\
\hline \multicolumn{2}{|l|}{ Group II vs. Group IIIA } & 0.913 & $>0.05$ \\
\hline \multicolumn{2}{|l|}{ Group II vs. Group IIIB } & 1.316 & $>0.05$ \\
\hline \multicolumn{2}{|l|}{ Group IIIA vs. Group IIIB } & 1.917 & $<0.05$ \\
\hline \multirow[t]{2}{*}{$\mathrm{PaCO} 2$} & $34.1 \pm 6.1$ & $37.9 \pm 6.1$ & $32.2 \pm 5.3$ \\
\hline & & $\mathrm{t}$ & $>0.05$ \\
\hline \multicolumn{2}{|l|}{ Group II vs. Group IIIA } & -1.137 & $>0.05$ \\
\hline \multicolumn{2}{|l|}{ Group II vs. Group IIIB } & 0.683 & $>0.05$ \\
\hline \multicolumn{2}{|l|}{ Group IIIA vs. Group IIIB } & 1.655 & \\
\hline \multirow[t]{2}{*}{$\mathrm{Pa} \mathrm{O} 2$} & $88.4 \pm 8.1$ & $86.1 \pm 7.8$ & $91.8 \pm 9.2$ \\
\hline & & $\mathrm{t}$ & $\mathrm{P}$ \\
\hline \multicolumn{2}{|l|}{ Group II vs. Group IIIA } & 0.531 & $>0.05$ \\
\hline \multicolumn{2}{|l|}{ Group II vs. Group IIIB } & -0.787 & $>0.05$ \\
\hline \multicolumn{2}{|l|}{ Group IIIA vs. Group IIIB } & -1.157 & $>0.05$ \\
\hline
\end{tabular}

Table 4: Descriptive and comparative statistics of PDGF in different groups:

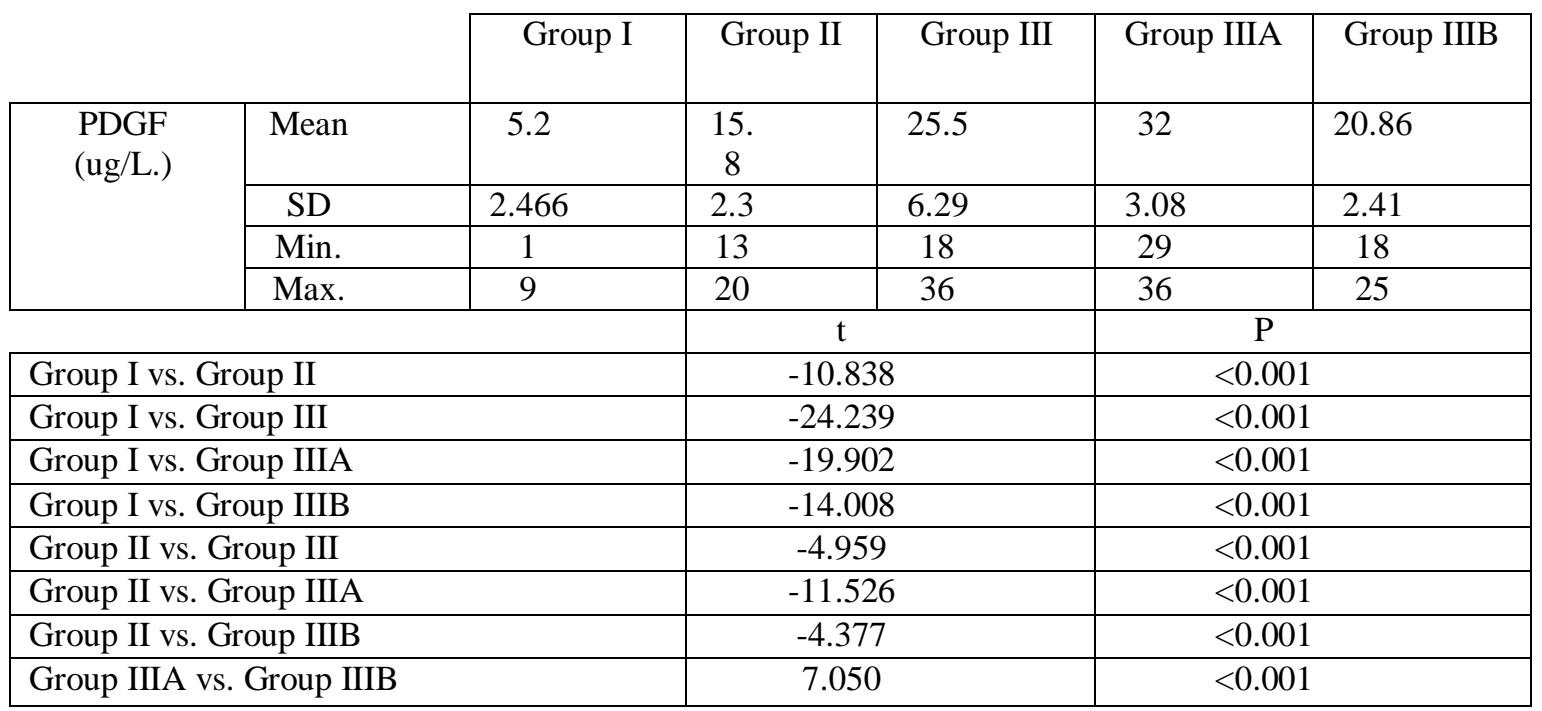


Table 5: Descriptive and comparative statistics of skin score in patients with SSc:

\begin{tabular}{|l|l|l|l|l|}
\cline { 3 - 5 } \multicolumn{2}{c|}{} & $\begin{array}{l}\text { Group } \\
\text { II }\end{array}$ & $\begin{array}{l}\text { Group } \\
\text { IIIA }\end{array}$ & $\begin{array}{l}\text { Group } \\
\text { IIIB }\end{array}$ \\
\hline \multirow{3}{*}{ Skin score } & Mean & 22.5 & 32.2 & 29.71 \\
\cline { 2 - 5 } & SD & 1.59 & 4.49 & 3.25 \\
\cline { 2 - 5 } & Min. & 19 & 26 & 25 \\
\cline { 2 - 5 } & Max. & 24 & 37 & 34 \\
\hline Group II vs. Group IIIA & t & p \\
\hline Group II vs. Group IIIB & -6.283 & $<0.001$ \\
\hline Group IIIA vs. Group IIIB & -6.11 & $<0.001$ \\
\hline
\end{tabular}

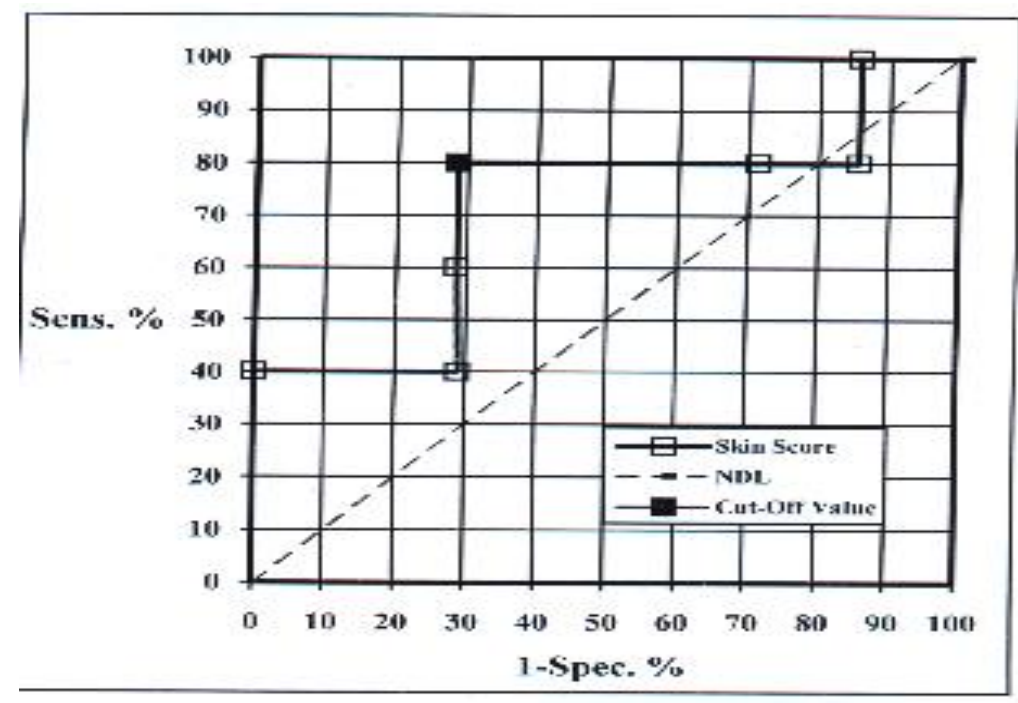

Skin Score $\mathbf{0 . 6 8 6}$

AUC

Fig. (1): ROC plot for skin score to detect best cut-off level to diagnose pulmonary affection in patients with diffuse systemic sclerosis.

\section{Discussion}

Systemic sclerosis presents a great deal of variability among different patients in the extent of skin and internal organ involvement, the pace of the disease and consequently, the prognosis. Lung involvement constitutes nowadays the major cause of morbidity and mortality in SSc. Pulmonary fibrosis in $\mathrm{SSc}$ is thought to be the consequence of interstitial inflammation. Early diagnosis and treatment is essential to prevent the deterioration of pulmonary function; improving the outcome in SSc patients (Valentini, 2003; Beretta et al., 2006 ; Allanore and Kahan, 2006).

Several fibro-proliferative mediators are believed to participate in the pathophysiology of pulmonary fibrosis. PDGF is one of the cytokines having a mitogenic effect on the myofibroblasts and the results of several studies support the fact that PDGF plays a role in the pathogenesis of SSc lung disease (Meloni et al., 2004) and (Jiminez and Derk, 2004). Also, the inhibition of PDGF signaling attenuates pulmonary fibrosis (Abdollahi et al., 2005).

The present study focused on the assessment of PDGF in the blood of patients suffering from various forms of systemic sclerosis and its relation to pulmonary involvement. We also tried to find the relation between the skin score (modified Rodnan TSS) and pulmonary affection, as 


\section{Manal Mahmoud et al}

the extent of skin sclerosis (skin score) was revealed to be a useful marker of both severity and prognosis in SSc and was successfully used in predicting renal crisis in SSc (Clements et al., 2000 ; De Marco et al., 2002).

In our study, serum PDGF in healthy volunteers ranged between 1 and 9 ug/l., and the mean was $5.2 \pm 2.4 \mathrm{ug} / \mathrm{l}$., Similar results were obtained by Sato et al., (2000) who studied serum PDGF in 30 healthy volunteers and reported a mean value of 5 ug/l.

Our results showed that SSc patients had significantly higher serum PDGF values than healthy subjects $(\mathrm{p}<0.001)$. This could be explained by the findings of Kawaguchi et al. (1999) and Sapadin et al. (2001) who reported that the fibroblasts derived from clinically affected skin areas of patients with SSc have the ability to overproduce several cytokines and growth factors as PDGF.

Our results revealed that serum PDGF values showed continuous significant increment with progression of the severity of the disease, as PDGF levels were significantly higher in patients with diffuse SSc than those with limited SSc. Moreover, the levels of PDGF were significantly higher in diffuse SSc patients with pulmonary affection than those without pulmonary affection. These results were supported by Sato et al. (2000) who found that the levels of PDGF in patients with diffuse SSc were significantly higher than those with limited SSc. Also we agree with Ludwicka et al. (1995) and Meloni et al. (2004) who found that there were high levels of PDGF and TGF- $\beta$ in broncho-alveolar lavage in patients with SSc than healthy controls. This result supported a role of PDGF and TGF- $\beta$ in the pathogenesis of pulmonary affection in SSc.

Our results also revealed the presence of a statistically significant correlation between serum PDGF and disease duration. This may be supported by Tamatani et al. (1998) who found that the levels of PDGF were increased from 1-3 years after disease onset. It is possible that TGF- $\beta$ is induced in the earliest phase of SSc and initiates fibrosis, followed by induction of PDGF that develops and/or maintains fibrosis (Sakkas, 2005). These results were reported by Gay et al. (1989) who observed elevated levels of PDGF as well as TGF- $\beta$ immunoreactivity in sclerodermatous skin and suggested an interplay of the two cytokines in the etiology of the disease. This was also supported by the finding that TGF- $\beta$ was expressed at the earliest stages in SSc skin and not maintained with progression of sclerosis (Varga and Bashey, 1995). In contrast PDGF mRNA expression was higher in dermis from the sclerotic stage than in that from the earlier inflammatory stage of patients with SSc (Igarashi et al., 1996; Mori et al., 1999).

There was also a significant negative correlation between PDGF and DLCO, which indicates that increased PDGF is associated with deterioration of the pulmonary function. Our findings reinforce the occurring sequence of events described by Ludwicka et al. (1995) and Meloni et al. (2004). The researchers stated that injury and disruption of the normal tissue architecture is accompanied by accumulation of inflammatory cells (mainly mononuclear phagocytes), platelets and type II pneumocytes. These cells produce cytokines, which participate in more local injury and inflammation and are chemoatractants for more fibroblasts. This vicious cycle of PDGF production, chemoatraction of fibroblasts associated with more PDGF production eventually leads to fibrosis. Vaillant et al. (2002) concluded that the chemoatractant activity (which is mediated by PDGF) seemed to be an independent indicator of lung fibroblast stimulation and activity.

Pulmonary fibrosis leads to impaired pulmonary function, which can be detected by forced vital capacity and diffusion capacity for carbon monoxide (Fishman, 1998 ; Khanna et al., 2005). Patients with raised PDGF levels have pulmonary fibrosis and decreased DLCO and FVC more often than those with normal PDGF. PDGF have inverse correlation with DLCO and FVC in patients with diffuse SSc. The hypothesized pathophysiology of pulmonary fibrosis motivated us to evaluate if PDGF or skin 
scoring could be an extra aid in detecting pulmonary fibrosis in SSc patients in case performance of FVC and DLCO is not available.

Our results and those of Sato et al. (2000) showed that all healthy subjects had PDGF < $10 \mathrm{ug} / \mathrm{l}$., and thus low PDGF tend to exclude the diagnosis of SSC. Moreover, all diffuse SSc patients suffering from pulmonary affection causing deterioration of their pulmonary functions had serum PDGF values $>25 \mathrm{ug} / \mathrm{l}$.

In this study total skin score was estimated for SSc patients as an indicator of the severity and progression of the disease. We tried to find the relation between the extent of the skin thickness (total skin score) and pulmonary fibrosis. Our results showed that progression of the clinical condition from limited to diffuse SSc was accompanied by a significant increase in the total skin score. There was also a tendency of positive correlation between the levels of PDGF and skin score $(p=0.05)$ in patients with diffuse SSc. This finding also reinforces the presence of the vicious cycle where skin fibroblasts produce PDGF, which in turn attracts more fibroblasts causing more damage to the tissues (Mori et al., 1999 ; Krein and Winston, 2002 ; Vaillant et al., 2002).

Our results also showed that the skin score was higher in diffuse SSc patients with pulmonary affection than those without, yet the difference was not significant. This may be due to its relative insensitivity or the small number of the patients included in this study. However, there was an inverse correlation between skin score and DLCO in patients with diffuse SSc $(\mathrm{p}<0.05)$, which may imply that skin score may tend to reflect pulmonary affection in patients with diffuse SSc. ROC plot was constructed to detect skin score best cut-off values, which was proved to be 29 and had a diagnostic sensitivity of $80 \%$ and specificity of $71.4 \%$ in detecting pulmonary affection in patients with diffuse SSc.

In conclusion, PDGF is a simple and easy laboratory test that tends to exclude the presence of SSc at a cut-off value of $10 \mathrm{ng} / \mathrm{ml}$ with $100 \%$ sensitivity and specificity. Similarly, it highly suggests the presence of pulmonary affection in patients with diffuse SSc at a cut-off level of $25 \mathrm{ng} / \mathrm{ml}$ with a diagnostic sensitivity and specificity of $100 \%$. Skin scoring system, is a simple physical examination measure for evaluating patients with systemic sclerosis. A skin score at a value of 29 was the best cut-off level to diagnose pulmonary affection in patients with diffuse SSc with a diagnostic sensitivity of $80 \%$ and specificity of $71.4 \%$. However, further studies are recommended on larger population to ensure the diagnostic efficiency of PDGF, and to test the applicability of our obtained cut-off values of the skin score and PDGF.

\section{References}

1. Abdollahi A, Li M, Ping G et al. (2005). Inhibition of platelet-derived growth factor signaling attenuates pulmonary fibrosis. J Exp. Med., 201(6): 925-935.

2. Alaibac M, Berti E, Chizzolini C, Fineschi S, Marzano A V and Pigozzi B. (2006). Role of cellular immunity in the pathogenesis of autoimmune skin disease. Clin Exp Rheumatol 1(40): 19-21.

3. Allanore $Y$ and Kahan A. (2006). Treatment of systemic sclerosis. Joint Bone Spine, 5 (1):26-30.

4. Beretta L, Caronni M, Raimondi M, Ponti A, Origgi L.(2006). Treatment improves pulmonary function in systemic sclerosis. Clin. Rheumatol., 14: 1127-1139.

5. Chiappini F, Zoli A, Mangeri L. (2005). Pulmonary involvement in systemic sclerosis. Monaldi Arch.Chest Dis., 63 (2):111-3.

6. Clements P J, Hurwitz E L, Wong W K et al. (2000).Skin thickness score as a predictor and correlate of outcome in systemic sclerosis: high-dose versus low-dose penicillamine trial. Arthritis Rheum., 43: 2445-54.

7. Clements $\mathbf{P}$ J, Lanchenbruch $\mathbf{P}$, Seibold J. (1995) Inter-and intraobserver variability of total skin thickness score (modified Rodnan TSS) in systemic sclerosis. J. Rheumatol., 22: 1281-1285.

8. Cotes J E. (1975). Textbook of lung function assessment and application in medicine. Third edition. Black Well Scientific Publication, Oxford, London, and Edinburgh.

9. De Marco P J, Weisman M H, Seibold J R, Furst D E, Wong W K et al. (2002). Predictors and outcomes of scleroderma renal crisis: the high-dose versus low-dose 


\section{Manal Mahmoud et al}

D-penicillamine in early diffuse systemic sclerosis trial. Arthritis Rheum., 46(11): 2983-9.

10. Fishman A P. (1998). Pulmonary diseases and disorders; textbook; Third edition; Mc Graw-Hill Book Company. Pulmonary manifestations of collagen vascular diseases. Chapter 73: 1126-1130.

11. Gay S, Jones R, Huang $\mathbf{G}$ and Ray R. (1998). mmunohistochemical demonstration of platelet derived growth factor (PDGF) and sisoncogene expression in scleroderma. J Invest Dermatol., 92: 301-303.

12. Highland $K \mathbf{B}$ and Silver $R$ M. (2005). New Developments in Scleroderma Interstitial Lung Disease. Curr Opin Rheumatol., 17 (6): 737-745.

13. Igarashi A, Nashiro $K$. and Kikuchi $K$. (1996). Connective tissue growth factor gene expression in tissue section from localized scleroderma, keloid and other fibrotic skin disorders. J Invest Dermatol 106: 729-733.

14. Jiminez S and Derk C. (2004).Following the Molecular Pathway toward an understanding of the pathogenesis of Systemic Sclerosis. Annals of Internal Medicine., 140: 37-50.

15. Kawaguchi Y, Hara $M$, Wright $\mathbf{T} M$. (1999). Endogenous IL-1 alpha from systemic sclerosis fibroblasts in PDGF-A. J Clin. Invest 103(9): 1253-60.

16. Khanna D, Clements P. and Furst D E. (2005). Correlation of the degree of the dyspnea with health related quality of life, functional abilities, and diffusion capacity for $\mathrm{CO}$ in patients with systemic sclerosis and active alveolitis. Arthritis Rheum., 52: 529-600.

17. Krein P M and Winston B M. (2002). Role for insulin like growth factor 1 and transforming growth factor beta in fibrotic lung disease. Chest .,122 (6): 289-293.

18. Le Roy E C, Krieg T. and Black C. (1988). Scleroderma (systemic sclerosis): Classification, subsets and pathogenesis. J Rheumatol 15: 202-205.

19. Ludwicka A, Ohba T, Trojanowska M, Yamakage A, Strange C, Smith T, Sutherland S. and Silver R M. (1995). Elevated levels of platelet derived growth factor and transformation growth factor-beta in bronchoalveolar lavage fluid from patients with scleroderma. J. Rheumatol., 22(10): 1876-83.

20. Masi A T, Rodman G P. and Medsger T A. (1980).Preliminary criteria for the classification of systemic sclerosis (scleroderma).
Arthritis Rheum., 23: 581-590.

21. Meloni F, Caporali R. and Marone Biaco A. (2004). Cytokine profile of broncho alveolar lavage in systemic sclerosis. Ann Rheum. Dis. 63: 892-894.

22. Mori T, Kawara S. and Shinozaki M. (1999). Role and interaction of connective tissue growth factor with transforming growth factor- $\beta$ in persistant fibrosis: a mouse fibrosis model. J. Cell Physiol., 181: 153-159.

23. Paulsson Y, Hammacher A, Heldin C H. and Westermark B. (2004). Possible positive autocrine feed back in the prereplicative phase of human fibroblasts. Nature., 328: 715-717.

24. Rodnan G P, Jablonska S. and Medsger T A Jr. (1979). Classification and nomenclature of progressive systemic sclerosis ( scleroderma ). Clin Rheum Dis., 5: 5-13.

25. Sakkas L I. (2005). New developments in the pathogenesis of Systemic Sclerosis. Autoimmunity., 38 (2): 113-6.

26. Sapadin A N, Esser A C, Fleischmajer R. (2001). Immunopathogenesis of Scleroderma- Evolving Concepts. The Mount Sinai Journal Of Medicine 68 (4, 5): 233-242.

27. Sato S, Nagaoka T, Hasegawa $M$, Tamatani T, Nakanishi T, Takigawa M, Takehara K. (2000).Serum levels of connective tissue growth factor are elevated in patients with systemic sclerosis: Association with extent of skin sclerosis and severity of pulmonary fibrosis. J. Rheumatol., 27 (1): 149-153.

28. Steen V D, Medsger T A Jr., Ziegler G. and Rodnan G P. (1980). Clinical comparison of two variants of progressive systemic sclerosis: diffuse scleroderma and C R E S T syndrome (abstract). Arthritis Rheum., 23: 752.

29. Tamatani T, Kobayashi H. and Tezuka K. (1998).Establishment of the enzyme-linked immunosorbent assay for connective tissue growth factor and its detection in the sera of biliary atresia. Biochem Biophys Res Commun ., 251: 748-752.

30. Vaillant P, Menard O, Vignaud J M, Martinet N. and Martinet Y. (2002). The role of cytokines in human lung fibrosis. Monaldi Arch Chest Dis., 51(2): 145-52.

31. Valentini G. (2003). The assessment of the patient with systemic sclerosis. Autoimmune Rev., 2: 370-6.

32. Varga J. and Bashey R I. (1995). Regulation of connective tissue synthesis in systemic sclerosis. Int Rev Immunol 12(24): 187-199. 


\section{عامل النمو المشتق من صفيحة الام و مدى سمك الجلد دلائل محتملة

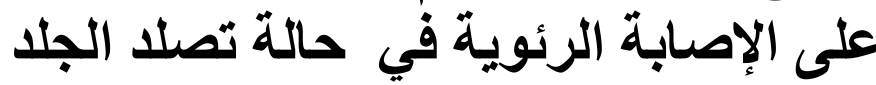



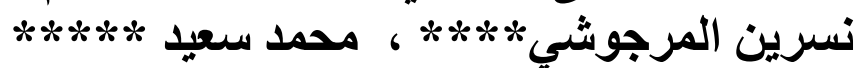

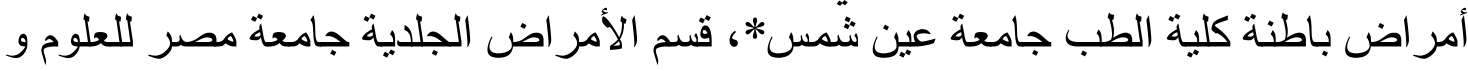
* التكنولو

قسم الصدر كلية الطب جامعة عين شمس*** ،قسم البحوث الطبية و الإشعاعية هيئة المو اد

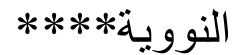

قسم الكيمياء الحيوية, وحدة رعاية الصدر كلية الطب جامعة عين شمس******ن

الهذف من هذه الدارسة هو تحديد مستويات عامل النمو المشتق من صفائح الدم في


بالرئة.

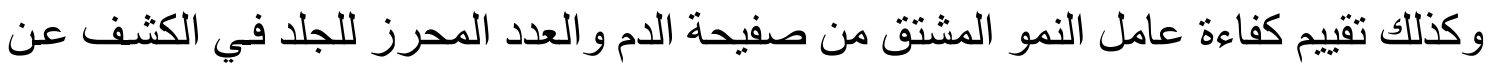

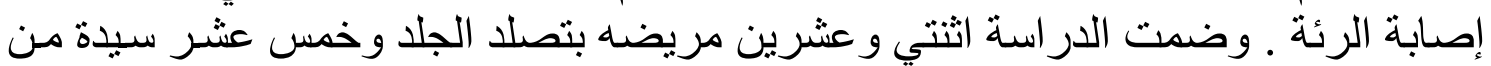

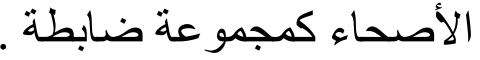

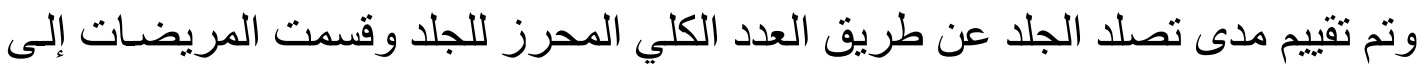

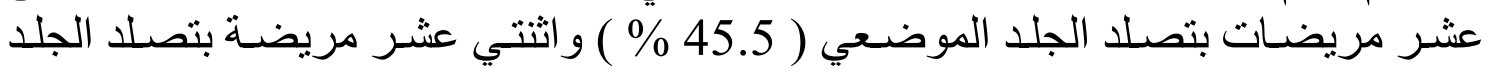

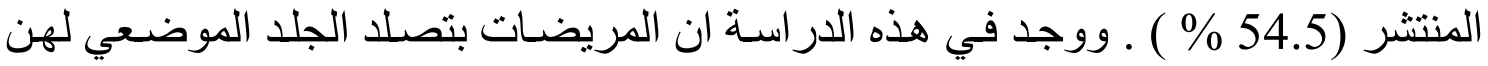

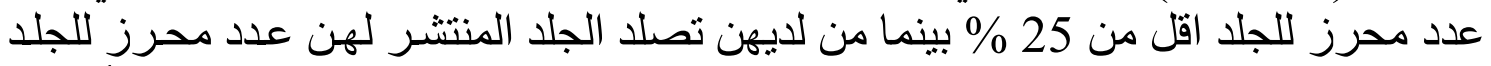



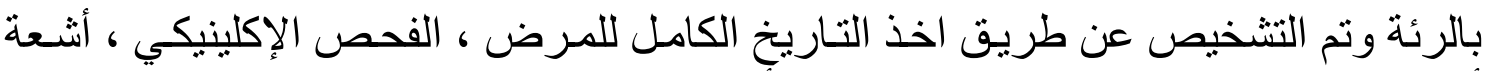

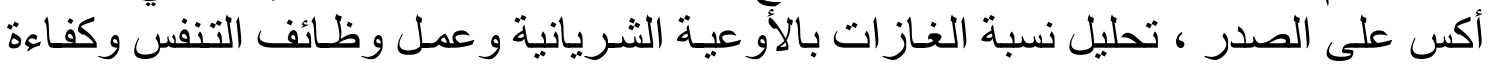



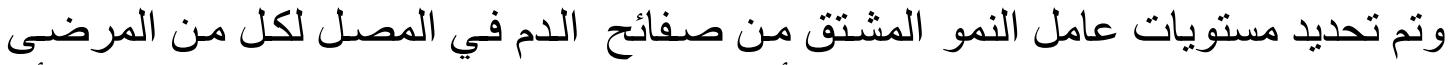

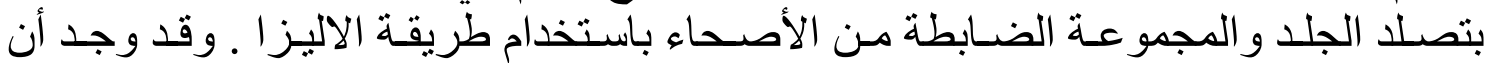

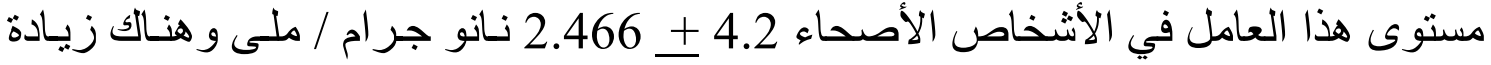



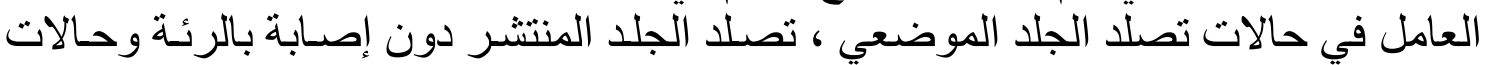

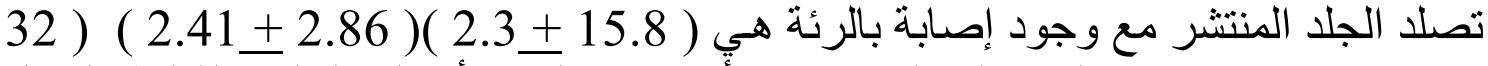

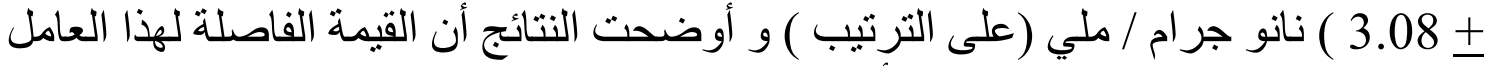

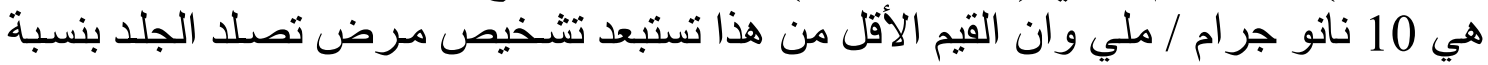

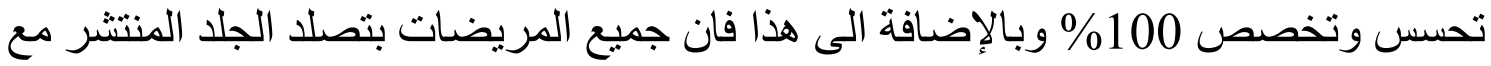

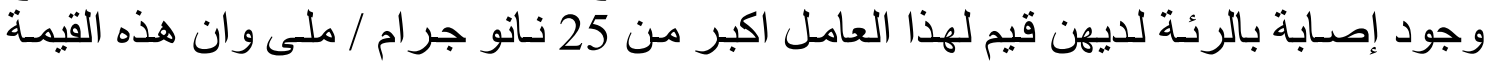

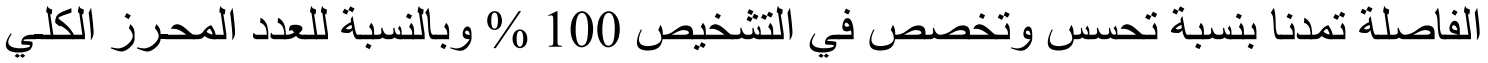

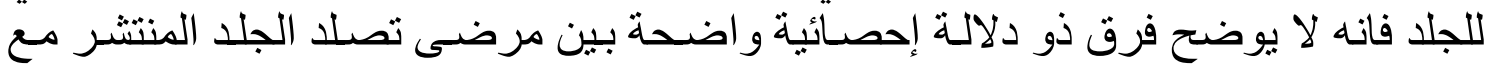


إصـابة بالرئـة او بـدون أصـابه بالرئسة ( 32.3 + 4.49 \% ) ( 29.71 +3.25\%) على

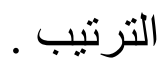
بينما وجد في مرضى تصلد الجلد المنتشر ميل لوجود علاقة إيجابية بين مستويات عامل

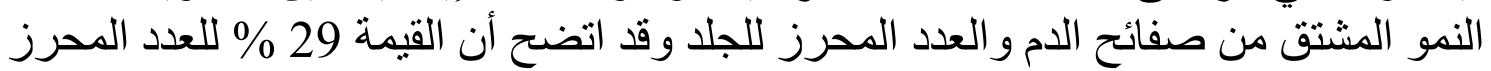

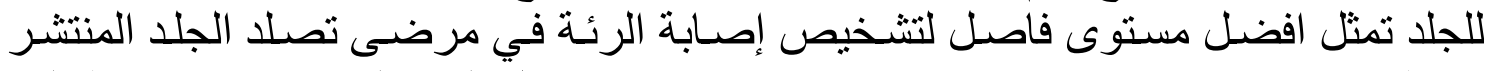

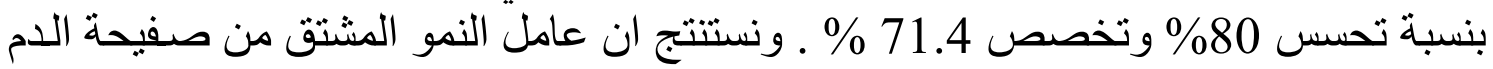

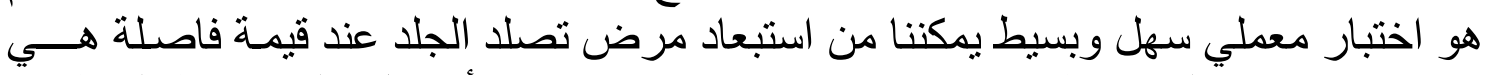

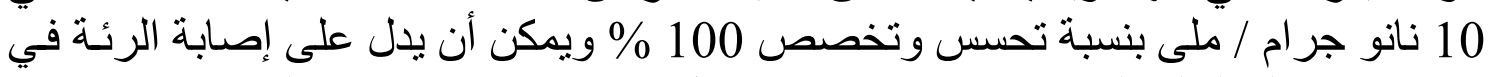

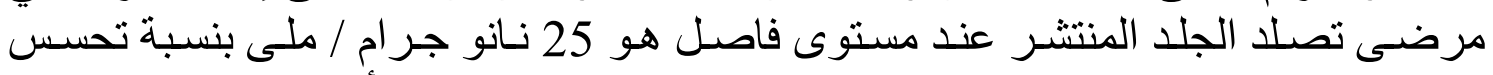

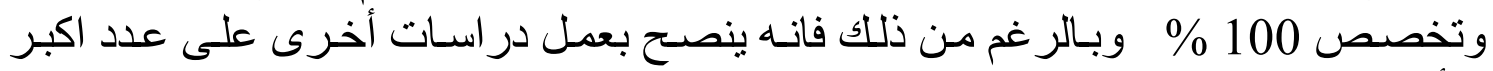


الدر اسة . 